\title{
Seminário de Integração como Dispositivo Pedagógico de Inovação Curricular no Ensino da Saúde: a Percepção do Estudante sobre o Paciente
}

\author{
Integration Seminars as Pedagogical \\ Devices for Curricular Innovation in Health \\ Education: Student Perceptions of Patients
}

Ramona Fernanda Ceriotti Toassi ${ }^{I}$ Danielle Stoffels ${ }^{I}$

Isabela Polesi Bergamaschi ${ }^{I}$ Alessandra Dutra da Silva

Pantelis Varvaki Rados ${ }^{I}$

\footnotetext{
PALAVRAS-CHAVE

- Educação Superior;

- Currículo;

- Ensino;

- Educação em Odontologia;

- Educação Médica.
}

\section{KEYWORDS}

- Higher Education;

- Curriculum;

- Teaching;

- Dental Education;

- Medical Education.

Recebido em: 26/01/2015

Aprovado em: 15/02/2016

\section{RESUMO}

Pesquisa exploratória documental de abordagem qualitativa cujo objetivo foi compreender como está se constituindo a formação do estudante de Odontologia em relação ao cuidado em saúde, a partir de uma atividade de ensino interdisciplinar ocorrida no segundo ano da formação do cirurgião-dentista. Foi realizado um levantamento retrospectivo do material produzido pelos estudantes do terceiro semestre do curso de Odontologia da Universidade Federal do Rio Grande do Sul, no Seminário de Integração IV, de 2006 a 2013. O corpus de análise foi formado por relatos de acompanhamento de pacientes e narrativas. Foram analisados 95 relatos de casos de pacientes e 67 narrativas pelo método da análise temática de conteúdo de Bardin. A análise do material resultou em 17 unidades de significação/categorias emergentes. A inclusão das narrativas no Seminário de Integração como estratégia metodológica de ensino na saúde trouxe a qualificação dos relatos e aproximou os estudantes do ser humano a ser cuidado, passando por sua queixa principal, história de vida e subjetividades. Currículos inovadores e integrados na área da saúde devem ser acompanhados permanentemente com base na experiência concreta nesta e em outras instituições de educação superior do País.

\section{ABSTRACT}

This documentary exploratory research project with a qualitative approach aimed to understand how dental students are being trained in terms of healthcare, by means of an interdisciplinary teaching activity held in the second year of dental school. A retrospective survey was performed from the material produced by the students during the third semester of the dentistry course at the Federal University of Rio Grande do Sul, by means of the IV Integration Seminar held in 2006-2013. The analysis corpus consisted of reports featuring patient monitoring and narratives. We analyzed 95 patient case reports and 67 narratives using the thematic analysis method on Bardin content. Analysis of the material resulted in 17 meaning units/emerging categories. The inclusion of narratives in the Integration Seminar as a methodological strategy for health education facilitated the qualification of reports and brought students closer to the human beings under care, by means of exposing the students to the patients' chief complaint, life history and subjective factors. The specific experiences of this study as well as those of other Brazilian educational institutions suggest that innovative and integrated curricula in the healthcare field must be implemented on a permanent basis. 


\section{INTRODUÇÃO}

Historicamente, a educação superior em Odontologia no Brasil seguiu padrões curriculares fragmentados, com conteúdos estanques, que enfatizam conhecimentos das ciências básicas e técnicas operatórias e limitados quanto aos aspectos preventivos e da saúde coletiva, com pouca ou nenhuma interconexão entre si, cabendo ao estudante a integração dos conteúdos ${ }^{1}$. Esta fragmentação reforçou os fundamentos do "taylorismo", ou seja, da visão quase puramente tecnicista e instrumental que caracterizou o ensino superior no País ${ }^{2}$.

Em 2002, quando as Diretrizes Curriculares Nacionais (DCN) dos cursos de graduação em Odontologia ${ }^{3}$ traçaram um perfil generalista do profissional a ser formado no Brasil e enunciaram habilidades e competências que deveriam ser desenvolvidas pelo cirurgião-dentista, novos caminhos foram buscados para responder ao desafio da formação. Esse contexto exigiu mudanças curriculares a partir da construção de projetos pedagógicos integrados e interdisciplinares, contemplando um olhar plural e a possibilidade de trabalho conjunto, que respeitasse as bases disciplinares específicas, mas buscando soluções compartilhadas para os problemas/necessidades das pessoas ${ }^{4}$.

Entendendo que mudanças na legislação não bastam para mudar uma lógica de formação ${ }^{5}$, o curso de graduação em Odontologia da Universidade Federal do Rio Grande do Sul (UFRGS) reestruturou seu currículo e implementou, em 2005, após três anos de discussão com a comunidade acadêmica, um novo modelo curricular baseado e orientado pelas DCN. O projeto pedagógico do curso contempla um ensino mais integrado às demandas sociais, pautado pelo panorama político do Brasil, baseando-se em competências e organizado em três momentos de formação - fundamental (básica), pré-profissional e profissional ${ }^{6,7}$.

Dos aspectos curriculares inovadores, destacam-se as Clínicas Odontológicas Integradas, os estágios de Acompanhamento Clínico, os estágios supervisionados nos cenários de prática do sistema público de saúde com ênfase na integração ensino-serviço-comunidade e os Seminários de Integração.

Com uma carga horária total de cinco créditos, os Seminários de Integração ocorrem do primeiro ao quarto semestre do curso de Odontologia e têm o objetivo de integrar os conhecimentos de cada semestre, sendo constituídos por professores de diferentes disciplinas e um professor facilitador dessa integração.

Neste contexto de formação baseada na integração curricular, o presente artigo busca compreender, por meio da análise do material produzido no Seminário de Integração IV, uma atividade de ensino interdisciplinar, de 2006 a 2013, como está se constituindo a formação do estudante da graduação em Odontologia em relação ao cuidado em saúde ao longo desta etapa curricular (segundo ano do curso).

\section{METODOLOGIA}

Trata-se de uma pesquisa exploratória documental, com abordagem qualitativa, que considera o contexto do problema de estudo, preocupando-se mais com significados do que com a frequência dos fatos apresentados ${ }^{8}$.

O corpus de análise foi composto pelas apresentações dos relatos de acompanhamento de pacientes e escrita de narrativas - levantamento retrospectivo do material produzido pelos estudantes do terceiro semestre do curso de graduação em Odontologia no Seminário de Integração IV - nas turmas de 2006 a 2013. O campo de investigação foi o curso de graduação em Odontologia da UFRGS.

O Seminário de Integração IV ocorre no terceiro semestre do curso de Odontologia e envolve conteúdos disciplinares de Fisiologia II, Patologia Básica, Semiologia, Técnica Radiográfica, Anatomia de Dentes Permanentes, Cariologia e Dentística. A organização pedagógica desse seminário caracteriza-se pela análise de casos clínicos por grupos menores de estudantes (até cinco alunos), que são orientados por docentes das disciplinas que compõem o semestre a discutir aspectos dos casos clínicos referentes às diferentes áreas da Odontologia. Os estudantes acompanham os pacientes atendidos nas Clínicas Odontológicas da Faculdade de Odontologia durante o semestre e, após, fazem a descrição do caso (por meio da escrita de narrativas orientadas) e apresentação dos relatos dos casos dos pacientes, segundo uma proposta de análise interdisciplinar. No momento da apresentação dos casos, todos os grupos de tutoria e professores tutores estão presentes para a discussão.

O método de ensino utilizado tem na tutoria a estratégia central. Cada grupo de estudantes tem um professor tutor que orienta o grupo. O processo tutorial construído no Seminário de Integração é presencial, com encontros quinzenais e ancorado na metodologia da problematização com base na vivência dos estudantes, acompanhando o atendimento de pacientes e do "caso clínico". Ao longo do seminário, os estudantes são estimulados a consultar todos os demais professores de áreas específicas envolvidos com a atividade de ensino, de modo a garantir uma visão integrada do paciente. Nesse processo de aprendizagem, os tutores são facilitadores que criam possibilidades, auxiliam, acompanham e avaliam. Ao mesmo tempo em que ensinam, os tutores também aprendem.

A avaliação dos estudantes foi processual ao longo do seminário e teve como fundamento básico a construção das narrativas e apresentação do caso clínico, considerando os cri- 
térios de interesse, participação, pontualidade, originalidade e qualidade do material apresentado, assim como discussão e envolvimento do grupo de tutoria com a situação apresentada. Além disso, foi feita uma avaliação escrita ao final do Seminário de Integração IV com questões que envolviam o conteúdo da apresentação de todos os grupos de tutoria e uma autoavaliação, com o objetivo de avaliar a percepção dos estudantes sobre a importância do seminário para a etapa da formação, identificando potencialidades e possíveis dificuldades.

As narrativas foram construídas pelos estudantes sob a orientação do professor tutor do grupo com base no acompanhamento dos pacientes atendidos nas Clínicas Odontológicas da Faculdade de Odontologia durante o semestre. Depois, os estudantes constroem a descrição do caso segundo uma proposta de análise interdisciplinar. Todas as narrativas eram lidas e revisadas pelo professor da Semiologia, além do professor tutor.

O foco da atividade de ensino não é a descrição de uma queixa, de um diagnóstico ou do tratamento do paciente, mas, sim, o reconhecimento da complexidade de como realizar o cuidado em saúde, entendendo o contexto em que esse paciente está inserido. É a possibilidade do olhar interdisciplinar, como estratégia de resistência à fragmentação dos saberes, articulando diferentes saberes, sem desqualificar o conhecimento especializado, que produzirá um novo conhecimento. A interdisciplinaridade se efetiva na medida em que os conhecimentos específicos de cada área se mantenham9

A análise das narrativas produzidas pelos estudantes justifica-se pela intenção da compreensão de experiências e diferentes pontos de vista de sujeitos em dado contexto ${ }^{10}$. A narrativa é entendida como uma ferramenta essencial na construção de significados para a existência humana e na descrição de experiências vividas ${ }^{11-13}$, assim como o seu contexto social, condição de saúde geral, experiências odontológicas, hábitos, história de vida, percepção sobre saúde bucal.

O material produzido foi analisado pelo método da análise temática de conteúdo ${ }^{14}$. O processo de explicitação, sistematização e expressão do conteúdo textual, promovido pela análise de conteúdo, foi organizado em três etapas: pré-análise (fase de organização e sistematização das ideias, em que ocorre a escolha dos documentos a serem analisados, a retomada das hipóteses e dos objetivos iniciais da pesquisa em relação ao material presente, e a elaboração de indicadores que orientarão a interpretação final); exploração do material (fase em que os dados brutos do material são codificados para se alcançar o núcleo de compreensão do texto); e tratamento dos resultados obtidos e interpretação (fase em que os dados são interpretados a fim de se tornarem significativos e válidos e de evidenciarem as informações obtidas).

\section{RESULTADOS}

Foram analisadas 95 apresentações com os relatos de casos de pacientes e 67 narrativas produzidas durante o Seminário de Integração IV, nas turmas de 2006 a 2013. Nas turmas de 2006 a 2008, estavam disponíveis as 13 apresentações que continham os relatos de caso dos pacientes acompanhados pelos estudantes nas Clínicas Integradas da Faculdade de Odontologia da UFRGS, as quais foram utilizadas como material pedagógico do Seminário de Integração. As narrativas foram incluídas na metodologia de ensino do Seminário IV a partir da turma de 2009 (Tabela 1).

\begin{tabular}{|cc|}
\hline & TABELA 1 \\
Caracterização do material produzido pelos estudantes \\
no Seminário de Integração IV do curso de graduação \\
em Odontologia da UFRGS, turmas de
\end{tabular}

* Material localizado no repositório digital do Seminário IV.

A análise do material produzido pelo Seminário de Integração IV resultou em 17 unidades de significação/categorias emergentes, que incluíram: informações demográficas e socioeconômicas dos pacientes; contexto familiar; queixa principal e diagnóstico; descrição da intervenção odontológica acompanhada pelos estudantes; história médica e odontológica pregressa e atual; exames complementares; forma de encaminhamento; hábitos comportamentais e parafuncionais; história de vida; percepção sobre saúde bucal; comportamento durante a consulta odontológica; foco do relato; área de especialidade do orientador e referencial teórico. O Quadro 1 apresenta as categorias e subcategorias que serviram de base para a análise dos resultados.

O Quadro 2 apresenta as informações dos relatos dos casos acompanhados pelos estudantes de graduação em Odontologia durante o Seminário de Integração IV. 


\section{QuAdro 1}

\section{Categorias e subcategorias de análise}

\section{Categorias}

1. Informações demográficas

2. Informações socioeconômicas

3. Contexto familiar

4. Queixa principal e diagnóstico

5. Descrição da intervenção odontológica acompanhada pelos estudantes

6. História médica pregressa e atual

7. História odontológica pregressa e atual

8. Exames complementares

9. Forma de encaminhamento

10. Hábitos comportamentais

11. Hábitos parafuncionais

12. História de vida

13. Percepção sobre saúde bucal

14. Comportamento durante a consulta odontológica

15. Foco do relato

16. Área de especialidade do orientador

17. Referencial teórico histórico familiar de doenças, tipo sanguíneo

Acesso a serviços odontológicos, última ida ao dentista, hábitos de higiene, tratamentos odontológicos prévios, orientação de higiene bucal prévia, presença/ condição das próteses, presença de lesões bucais ou ausência

\section{Subcategorias}

Sexo, idade, local de residência, cor da pele, estado civil, naturalidade

Escolaridade, ocupação, renda familiar ou ausente

Número de filhos, com quem mora, número de irmãos

Presente ou ausente

Presente ou ausente

Estado geral de saúde, medicação atual, alergias, cirurgias feitas anteriormente,

Radiografias (periapicais, panorâmicas, interproximais e oclusal), ecografia, biópsia, hemograma, glicemia em jejum, diascopia, tomografia cone bean, testes de fluxo salivar, testes de vitalidade pulpar

Presente ou ausente

Tabagismo, consumo de álcool e drogas, hábitos alimentares, prática de exercícios físicos, exposição solar ou ausente

Bruxismo

Relato de violência doméstica, de preconceito ou ausente

Presente ou ausente

Presente ou ausente

Queixa principal do paciente, especialidade do orientador, percepção do paciente como um todo - integral/interdisciplinar

Presente ou ausente

Livros, Trabalhos acadêmicos, Artigos ou Ausente

\begin{tabular}{|c|c|c|c|c|c|c|c|c|}
\hline \multicolumn{9}{|c|}{$\begin{array}{l}\text { QUADRo } 2 \\
\text { Informações dos relatos de caso de pacientes acompanhados pelos estudantes de graduação em Odontologia } \\
\text { no Seminário de Integração IV. } \\
\text { Curso de graduação em Odontologia, UFRGS, } 2006 \text { a } 2013\end{array}$} \\
\hline Categorias & Turmas 2006 & Turmas 2007 & Turmas 2008 & Turmas 2009 & Turmas 2010 & Turmas 2011 & Turmas 2012 & Turmas 2013 \\
\hline $\begin{array}{l}\text { Informações } \\
\text { demográficas }\end{array}$ & $\begin{array}{l}\text { Sexo } \\
\text { Idade } \\
\text { Local de } \\
\text { residência }\end{array}$ & $\begin{array}{l}\text { Sexo } \\
\text { Idade } \\
\text { Local de } \\
\text { residência } \\
\text { Cor da pele } \\
\text { Estado civil }\end{array}$ & $\begin{array}{l}\text { Sexo } \\
\text { Idade } \\
\text { Local de } \\
\text { residência } \\
\text { Cor da pele } \\
\text { Estado civil }\end{array}$ & $\begin{array}{c}\text { Sexo } \\
\text { Idade } \\
\text { Local de } \\
\text { residência } \\
\text { Cor da pele } \\
\text { Estado civil } \\
\text { Naturalidade }\end{array}$ & $\begin{array}{c}\text { Sexo } \\
\text { Idade } \\
\text { Local de } \\
\text { residência } \\
\text { Cor da pele } \\
\text { Estado civil } \\
\text { Naturalidade }\end{array}$ & $\begin{array}{l}\text { Sexo } \\
\text { Idade } \\
\text { Residência } \\
\text { Cor da pele } \\
\text { Estado civil } \\
\text { Naturalidade }\end{array}$ & $\begin{array}{c}\text { Sexo } \\
\text { Idade } \\
\text { Local de } \\
\text { residência } \\
\text { Cor da pele } \\
\text { Estado civil } \\
\text { Naturalidade }\end{array}$ & $\begin{array}{c}\text { Sexo } \\
\text { Idade } \\
\text { Local de } \\
\text { residência } \\
\text { Estado civil } \\
\text { Naturalidade }\end{array}$ \\
\hline $\begin{array}{l}\text { Informações } \\
\text { socioeconômicas }\end{array}$ & Ausente & $\begin{array}{l}\text { Escolaridade } \\
\text { Ocupação }\end{array}$ & $\begin{array}{l}\text { Escolaridade } \\
\text { Ocupação } \\
\text { Renda familiar }\end{array}$ & $\begin{array}{l}\text { Escolaridade } \\
\text { Ocupação } \\
\text { Renda familiar }\end{array}$ & $\begin{array}{l}\text { Escolaridade } \\
\text { Ocupação } \\
\text { Renda familiar }\end{array}$ & $\begin{array}{c}\text { Escolaridade } \\
\text { Ocupação } \\
\text { Renda Familiar }\end{array}$ & $\begin{array}{l}\text { Escolaridade } \\
\text { Ocupação } \\
\text { Renda Familiar }\end{array}$ & $\begin{array}{l}\text { Escolaridade } \\
\text { Ocupação } \\
\text { Renda Familiar }\end{array}$ \\
\hline Contexto familiar & Ausente & Ausente & $\begin{array}{l}\text { Número de } \\
\text { filhos } \\
\text { Cuidador de } \\
\text { filha depressiva }\end{array}$ & $\begin{array}{l}\text { Número de } \\
\text { filhos } \\
\text { Com quem mora }\end{array}$ & $\begin{array}{l}\text { Número de } \\
\text { filhos } \\
\text { Com quem mora }\end{array}$ & $\begin{array}{l}\text { Número de } \\
\text { filhos } \\
\text { Com quem mora } \\
\text { Número de } \\
\text { irmãos }\end{array}$ & $\begin{array}{l}\text { Número de } \\
\text { filhos } \\
\text { Com quem mora } \\
\text { Número de } \\
\text { irmãos }\end{array}$ & $\begin{array}{l}\text { Número de } \\
\text { filhos } \\
\text { Com quem mora } \\
\text { Número de } \\
\text { irmãos }\end{array}$ \\
\hline $\begin{array}{c}\text { Queixa principal e } \\
\text { diagnóstico }\end{array}$ & Presente & Presente & Presente & Presente & Presente & Presente & Presente & Presente \\
\hline
\end{tabular}




\begin{tabular}{|c|c|c|c|c|c|c|c|c|}
\hline \multicolumn{9}{|c|}{$\begin{array}{r}\text { Informações dos relatos de caso de pacientes acompanhados pelos estu } \\
\text { no Seminário de Integração IV. }\end{array}$} \\
\hline Categorias & Turmas 2006 & Turmas 2007 & Turmas 2008 & Turmas 2009 & Turmas 2010 & Turmas 2011 & Turmas 2012 & Turmas 2013 \\
\hline $\begin{array}{l}\text { Descrição da } \\
\text { intervenção } \\
\text { odontológica } \\
\text { acompanhada } \\
\text { pelos estudantes }\end{array}$ & Presente & Ausente & Presente & Presente & Presente & Presente & Presente & Presente \\
\hline $\begin{array}{l}\text { História médica } \\
\text { pregressa e atual }\end{array}$ & $\begin{array}{l}\text { Estado geral de } \\
\text { saúde (condições } \\
\text { patológicas } \\
\text { presentes) } \\
\text { Medicação atual }\end{array}$ & $\begin{array}{l}\text { Estado geral de } \\
\text { saúde (condições } \\
\text { patológicas } \\
\text { presentes) } \\
\text { Medicação atual }\end{array}$ & $\begin{array}{c}\text { Estado geral de } \\
\text { saúde (condições } \\
\text { patológicas } \\
\text { presentes) } \\
\text { Medicação atual } \\
\text { Alergias } \\
\text { Cirurgias } \\
\text { anteriores }\end{array}$ & $\begin{array}{c}\text { Estado geral de } \\
\text { saúde (condições } \\
\text { patológicas } \\
\text { presentes) } \\
\text { Medicação atual } \\
\text { Alergias } \\
\text { Cirurgias } \\
\text { anteriores } \\
\text { Histórico } \\
\text { familiar de } \\
\text { doenças }\end{array}$ & $\begin{array}{c}\text { Estado geral de } \\
\text { saúde (condições } \\
\text { patológicas } \\
\text { presentes) } \\
\text { Medicação atual } \\
\text { Alergias } \\
\text { Cirurgias } \\
\text { anteriores } \\
\text { Histórico } \\
\text { familiar de } \\
\text { doenças } \\
\text { Tipo sanguíneo }\end{array}$ & $\begin{array}{c}\text { Estado geral de } \\
\text { saúde (condições } \\
\text { patológicas } \\
\text { presentes) } \\
\text { Medicação atual } \\
\text { Alergias } \\
\text { Cirurgias } \\
\text { anteriores } \\
\text { Histórico } \\
\text { familiar de } \\
\text { doenças }\end{array}$ & $\begin{array}{c}\text { Estado geral de } \\
\text { saúde (condições } \\
\text { patológicas } \\
\text { presentes) } \\
\text { Medicação atual } \\
\text { Alergias } \\
\text { Cirurgias } \\
\text { anteriores } \\
\text { Histórico } \\
\text { familiar de } \\
\text { doenças } \\
\text { Tipo sanguíneo }\end{array}$ & $\begin{array}{c}\text { Estado geral de } \\
\text { saúde (condições } \\
\text { patológicas } \\
\text { presentes) } \\
\text { Medicação atual } \\
\text { Cirurgias } \\
\text { anteriores } \\
\text { Histórico } \\
\text { familiar de } \\
\text { doenças }\end{array}$ \\
\hline $\begin{array}{l}\text { História } \\
\text { odontológica } \\
\text { pregressa e atual }\end{array}$ & Ausente & $\begin{array}{l}\text { Acesso a serviços } \\
\text { odontológicos } \\
\text { Última ida ao } \\
\text { dentista } \\
\text { Hábitos de higiene }\end{array}$ & $\begin{array}{c}\text { Acesso a } \\
\text { serviços } \\
\text { odontológicos } \\
\text { Última ida ao } \\
\text { dentista } \\
\text { Hábitos de } \\
\text { higiene }\end{array}$ & $\begin{array}{c}\text { Hábitos } \\
\text { de higiene } \\
\text { Tratamentos } \\
\text { odontológicos } \\
\text { prévios } \\
\text { Orientação de } \\
\text { higiene bucal } \\
\text { prévia }\end{array}$ & $\begin{array}{c}\text { Hábitos } \\
\text { de higiene } \\
\text { Tratamentos } \\
\text { odontológicos } \\
\text { prévios } \\
\text { Orientação de } \\
\text { higiene bucal } \\
\text { prévia } \\
\text { Presença/ } \\
\text { condição das } \\
\text { próteses } \\
\text { Presença de } \\
\text { lesões bucais }\end{array}$ & $\begin{array}{c}\text { Acesso a } \\
\text { serviços } \\
\text { odontológicos } \\
\text { Última ida ao } \\
\text { dentista } \\
\text { Hábitos de } \\
\text { higiene } \\
\text { Tratamentos } \\
\text { odontológicos } \\
\text { prévios } \\
\text { Orientação de } \\
\text { higiene bucal } \\
\text { prévia } \\
\text { Presença/ } \\
\text { condição das } \\
\text { próteses } \\
\text { Presença de } \\
\text { lesões bucais }\end{array}$ & $\begin{array}{c}\text { Hábitos } \\
\text { de higiene } \\
\text { Tratamentos } \\
\text { odontológicos } \\
\text { prévios } \\
\text { Orientação de } \\
\text { higiene bucal } \\
\text { prévia } \\
\text { Presença de } \\
\text { lesões bucais }\end{array}$ & $\begin{array}{c}\text { Acesso a } \\
\text { serviços } \\
\text { odontológicos } \\
\text { Última ida ao } \\
\text { dentista } \\
\text { Tratamentos } \\
\text { odontológicos } \\
\text { prévios } \\
\text { Presença de } \\
\text { lesões bucais }\end{array}$ \\
\hline $\begin{array}{c}\text { Exames } \\
\text { complementares }\end{array}$ & $\begin{array}{l}\text { Radiografias } \\
\text { periapicais }\end{array}$ & $\begin{array}{l}\text { Radiografias } \\
\text { periapicais } \\
\text { panorâmicas }\end{array}$ & $\begin{array}{c}\text { Radiografias } \\
\text { panorâmicas } \\
\text { Biópsia } \\
\text { Hemograma }\end{array}$ & $\begin{array}{c}\text { Radiografias } \\
\text { (periapicais, } \\
\text { panorâmicas, } \\
\text { interproximais e } \\
\text { oclusal) } \\
\text { Ecografia } \\
\text { Biópsia } \\
\text { Hemograma } \\
\text { Glicemia em } \\
\text { jejum } \\
\text { Diascopia } \\
\text { Tomografia cone } \\
\text { bean }\end{array}$ & $\begin{array}{c}\text { Radiografias } \\
\text { (periapicais, } \\
\text { panorâmicas e } \\
\text { interproximais) } \\
\text { Biópsia } \\
\text { Hemograma } \\
\text { Tomografia cone } \\
\text { bean } \\
\text { Diário alimentar }\end{array}$ & $\begin{array}{c}\text { Radiografias } \\
\text { (periapicais e } \\
\text { panorâmicas) } \\
\text { Biópsia } \\
\text { Diário alimentar } \\
\text { Teste de fluxo } \\
\text { salivar }\end{array}$ & $\begin{array}{c}\text { Radiografias } \\
\text { (periapicais, } \\
\text { panorâmicas e } \\
\text { interproximais) } \\
\text { Teste de fluxo } \\
\text { salivar } \\
\text { Teste de } \\
\text { sensibilidade } \\
\text { pulpar }\end{array}$ & $\begin{array}{l}\text { Radiografias } \\
\text { (periapicais e } \\
\text { panorâmicas) } \\
\text { Biópsia }\end{array}$ \\
\hline $\begin{array}{c}\text { Forma de } \\
\text { encaminhamento }\end{array}$ & Ausente & Ausente & $\begin{array}{l}\text { Presente em } \\
\text { alguns relatos }\end{array}$ & Presente & $\begin{array}{l}\text { Presente em } \\
\text { alguns relatos }\end{array}$ & Ausente & Presente & Ausente \\
\hline $\begin{array}{c}\text { Hábitos } \\
\text { comportamentais }\end{array}$ & Ausente & $\begin{array}{l}\text { Quantidade e } \\
\text { frequência de } \\
\text { cigarros e bebidas } \\
\text { alcoólicas } \\
\text { Presença } \\
\text { de hábitos } \\
\text { alimentares }\end{array}$ & $\begin{array}{l}\text { Quantidade } \\
\text { e frequência } \\
\text { de cigarros } \\
\text { e bebidas } \\
\text { alcoólicas } \\
\text { Presença } \\
\text { de hábitos } \\
\text { alimentares }\end{array}$ & $\begin{array}{l}\text { Quantidade } \\
\text { e frequência } \\
\text { de cigarros } \\
\text { e bebidas } \\
\text { alcoólicas } \\
\text { Usuário de } \\
\text { drogas }\end{array}$ & $\begin{array}{l}\text { Quantidade } \\
\text { e frequência } \\
\text { de cigarros } \\
\text { e bebidas } \\
\text { alcoólicas } \\
\text { Presença } \\
\text { de hábitos } \\
\text { alimentares } \\
\text { Relato de } \\
\text { exposição solar }\end{array}$ & $\begin{array}{l}\text { Quantidade } \\
\text { e frequência } \\
\text { de cigarros } \\
\text { e bebidas } \\
\text { alcoólicas } \\
\text { Usuário de } \\
\text { drogas } \\
\text { Presença } \\
\text { de hábitos } \\
\text { alimentares } \\
\text { Relato de } \\
\text { exposição solar }\end{array}$ & $\begin{array}{l}\text { Quantidade } \\
\text { e frequência } \\
\text { de cigarros } \\
\text { e bebidas } \\
\text { alcoólicas } \\
\text { Presença } \\
\text { de hábitos } \\
\text { alimentares } \\
\text { Prática de } \\
\text { exercícios físicos } \\
\text { Relato de } \\
\text { exposição solar }\end{array}$ & $\begin{array}{c}\text { Quantidade } \\
\text { e frequência } \\
\text { de cigarros } \\
\text { e bebidas } \\
\text { alcoólicas } \\
\text { Presença } \\
\text { de hábitos } \\
\text { alimentares } \\
\text { Prática de } \\
\text { exercícios físicos } \\
\text { Relato de } \\
\text { exposição solar }\end{array}$ \\
\hline
\end{tabular}




\begin{tabular}{|c|c|c|c|c|c|c|c|c|}
\hline \multicolumn{9}{|c|}{$\begin{array}{l}\text { Informações dos relatos de caso de pacientes acompanhados pelos estudantes de gra } \\
\text { no Seminário de Integração IV. } \\
\text { Curso de graduação em Odontologia, UFRGS, } 2006 \text { a } 2013\end{array}$} \\
\hline Categorias & Turmas 2006 & Turmas 2007 & Turmas 2008 & Turmas 2009 & Turmas 2010 & Turmas 2011 & Turmas 2012 & Turmas 2013 \\
\hline $\begin{array}{c}\text { Hábitos } \\
\text { parafuncionais }\end{array}$ & Ausente & Bruxismo & Ausente & Bruxismo & Bruxismo & Bruxismo & Ausente & Ausente \\
\hline História de vida & Ausente & Ausente & Ausente & $\begin{array}{l}\text { Relato de } \\
\text { violência } \\
\text { doméstica pela } \\
\text { cuidadora }\end{array}$ & $\begin{array}{c}\text { Relato de } \\
\text { preconceito }\end{array}$ & $\begin{array}{c}\text { Relato de } \\
\text { preconceito }\end{array}$ & $\begin{array}{c}\text { Relato de } \\
\text { preconceito }\end{array}$ & Ausente \\
\hline $\begin{array}{l}\text { Percepção sobre } \\
\text { saúde bucal }\end{array}$ & Ausente & Ausente & Ausente & Presente & Presente & Presente & Presente & Presente \\
\hline $\begin{array}{l}\text { Comportamento } \\
\text { durante a consulta } \\
\text { odontológica }\end{array}$ & Ausente & Ausente & Ausente & Presente & Presente & Presente & Presente & Presente \\
\hline Foco do relato & $\begin{array}{l}\text { Queixa principal } \\
\text { do paciente }\end{array}$ & $\begin{array}{l}\text { Especialidade do } \\
\text { orientador }\end{array}$ & $\begin{array}{l}\text { Queixa principal } \\
\text { do paciente }\end{array}$ & $\begin{array}{l}\text { Percepção } \\
\text { do paciente } \\
\text { como um todo } \\
\text { - integral/ } \\
\text { interdisciplinar }\end{array}$ & $\begin{array}{l}\text { Percepção } \\
\text { do paciente } \\
\text { como um todo } \\
\text { - integral/ } \\
\text { interdisciplinar }\end{array}$ & $\begin{array}{c}\text { Percepção } \\
\text { do paciente } \\
\text { como um todo } \\
\text { - integral/ } \\
\text { interdisciplinar }\end{array}$ & $\begin{array}{c}\text { Percepção } \\
\text { do paciente } \\
\text { como um todo } \\
\text { - integral/ } \\
\text { interdisciplinar }\end{array}$ & $\begin{array}{c}\text { Percepção } \\
\text { do paciente } \\
\text { como um todo } \\
\text { - integral/ } \\
\text { interdisciplinar }\end{array}$ \\
\hline $\begin{array}{l}\text { Área de } \\
\text { especialidade do } \\
\text { orientador }\end{array}$ & Ausente & Presente & Presente & Presente & Presente & Presente & Presente & Presente \\
\hline Referencial teórico & Ausente & $\begin{array}{c}\text { Livros } \\
\text { Artigos } \\
\text { científicos }\end{array}$ & $\begin{array}{l}\text { Artigos } \\
\text { científicos }\end{array}$ & $\begin{array}{l}\text { Livros } \\
\text { Artigos } \\
\text { científicos } \\
\text { Tese de } \\
\text { doutorado }\end{array}$ & $\begin{array}{c}\text { Livros } \\
\text { Artigos } \\
\text { científicos }\end{array}$ & $\begin{array}{c}\text { Livros } \\
\text { Artigos } \\
\text { científicos }\end{array}$ & $\begin{array}{c}\text { Livros } \\
\text { Artigos } \\
\text { científicos }\end{array}$ & $\begin{array}{c}\text { Livros } \\
\text { Artigos } \\
\text { científicos }\end{array}$ \\
\hline
\end{tabular}

A partir da turma de 2009, com a possibilidade de análise das narrativas produzidas, notou-se a ampliação do conjunto de observações percebidas pelos estudantes e a presença de novas informações agregadas aos relatos. Nesse contexto diferenciado, destacam-se as informações voltadas ao contexto familiar dos pacientes, histórico familiar de doenças, hábitos comportamentais, história de vida (relatos de violência doméstica, preconceito), além de informações subjetivas (percepção sobre a condição de saúde bucal, comportamento durante as consultas odontológicas).

Quanto à percepção sobre a condição de saúde bucal, a influência do estado da boca e dentes sobre a vida das pessoas, causando estresse, desconforto/vergonha ao sorrir e até prejuízo no trabalho por falta dos dentes anteriores ou por questões estéticas, foi um diferencial importante em relação aos relatos das turmas de 2009 a 2013.

Paciente falou que não trabalha mais no comércio pelo desconforto que a falta de dentes na região anterior lhe oferece. (Turma 2009)

Paciente preocupado com a aparência dos dentes e como isso interfere na sua vida social. (Turma 2010)

Paciente preocupada com relação à estética. (Turma 2012)

Paciente preocupada com sua saúde bucal. (Turma 2013)
Os relatos sobre o comportamento dos pacientes durante as consultas mostraram percepções e sentimentos dos pacientes percebidos pelos estudantes (medo de dentista, preocupação, ansiedade, tranquilidade, nervosismo, curiosidade, expectativa frente ao tratamento). Essa unidade de análise subjetiva dos pacientes foi assim expressa pelos estudantes nas narrativas:

Paciente afirmou ter muito medo de dentista, apresentou-se bastante preocupado para saber o que era a lesão que o fez procurar atendimento; mostrou-se um pouco ansioso e pensou ter algo grave, devido ao fato de muitas pessoas estarem analisando seu caso; afirmou ter medo de ter câncer. (Turma 2009)

Paciente muito tranquila durante as consultas, permanecendo de maneira confortável e relaxada, conversando bastante e atenta ao que estava acontecendo ao seu redor; muito ansiosa e preocupada com o procedimento, sendo o seu maior receio a anestesia; paciente é tímida; paciente preocupado com a aparência dos dentes e como isso interfere na sua vida social, tranquilo e receptivo durante a consulta; paciente estava consciente de que a saúde precisa ser recuperada antes do tratamento estético; paciente informou ter gostado do atendimento e mostrou-se muito prestativo na hora de relatar 
os fatos e de responder às perguntas feitas a ele durante o diálogo. (Turma 2010)

Paciente apresenta nervosismo frente ao dentista: "Medo daquele barulhinho, por isso fui empurrando com a barriga"; paciente apresenta nervosismo frente ao dentista e demorou até ir à procura de atendimento; paciente sentiu-se desconfortável ao tirar as fotos para o trabalho. (Turma 2011)

Paciente demonstrou valorizar a saúde bucal de maneira restrita, pois sua ideia de saúde está vinculada apenas à falta de sintomatologia, ou seja, ele se mostra satisfeito; demonstrou grande interesse sobre a maneira como ia ocorrer o seu tratamento, questionou os profissionais que a atenderam, mostrando-se bastante curiosa sobre os procedimentos a serem efetuados e propondo hipótese sobre a causa do seu problema; paciente não se importa com a aparência e ainda relata que vai extrair mais dentes; não tem medo de ir ao dentista nem tem vivenciado experiências desagradáveis; não se constrange com a sua estética bucal; paciente possui uma grande expectativa quanto a sua nova prótese. (Turma 2012)

Primeira experiência com dentista foi traumática; paciente extremamente contente, inclusive a mesma referiu: "agora vou poder sorrir bastante"; paciente relata conhecer os hábitos de higiene e preocupar-se com sua saúde bucal; paciente preocupada com sua saúde bucal. (Turma 2013)

Verifica-se, ainda, que, a partir da escrita das narrativas, o foco dos relatos dos estudantes deixou de se centrar na queixa principal do paciente ou na área da especialidade do orientador (Turmas de 2006 a 2008), ampliando-se para um olhar integral e interdisciplinar do paciente (Turmas de 2009 a 2013). Também merece destaque a inclusão do referencial teórico, sempre presente, a partir da turma de 2007.

\section{DISCUSSÃO}

A inovação curricular está na ordem do dia quando o lócus de discussão é o ensino superior, em especial os cursos de formação em saúde ${ }^{15}$.

O modelo de ensino fragmentado e desarticulado dos determinantes sociais no processo saúde-doença contribuiu para a perda do entendimento de que o foco da atenção nos cursos da saúde é o paciente, entendido como uma pessoa única, que deve ser considerada em sua totalidade, incluindo também, além da sua queixa principal/enfermidade, aspectos voltados ao seu contexto social, psicológico e espiritual ${ }^{16}$.

As dimensões subjetivas e sociais das práticas em saúde ganharam valorização com a instituição da Política Nacional de Humanização - Humaniza SUS -, a qual tem a humanização como eixo norteador das práticas de atenção e gestão em todas as instâncias do Sistema Único de Saúde (SUS). Nessa perspectiva, a abordagem integral do ser humano busca a superação da "fragmentação do olhar e intervenções sobre os sujeitos, que devem ser vistos em suas inseparáveis dimensões biopsicossociais" (p. 63) ${ }^{17}$.

O cuidado integral à saúde volta-se, assim, ao ser humano como sujeito, e não como objeto, integrando as partes de um organismo vivo, dilacerado e objetivado pelo olhar reducionista do entendimento de saúde, e reconhece nele um sujeito, um semelhante, reorientando o modelo do cuidado ${ }^{18}$.

Para os cursos da área da saúde, incluindo a Odontologia, a implantação das Diretrizes Curriculares Nacionais (DCN) em 2002 e, antes disso, da Lei de Diretrizes e Bases da Educação (LDB) ${ }^{19}$ trouxe a necessidade de formação do profissional da saúde capacitado não exclusivamente nos aspectos técnicos da profissão, mas também nos éticos, humanistas e de cidadania. Com as Diretrizes, vieram as mudanças e as inovações curriculares nos cursos de graduação em Odontologia e o direcionamento para uma formação centrada no paciente, voltada ao cuidado em saúde, conectada ao SUS e à experiência vivida $^{20,21}$. Os currículos rígidos, individualistas, compostos por disciplinas cada vez mais fragmentadas foram sendo analisados e repensados, dando lugar a currículos flexíveis, dirigidos para a aquisição de um perfil e competências profissionais, com abordagens pedagógicas produtoras de sentido, diversificação de cenários de prática e de metodologias de aprendizagem, habilidades, atitudes ${ }^{22,23,24}$.

No curso de Odontologia da UFRGS, os Seminários de Integração destacaram-se na proposta da reestruturação curricular efetivada a partir de 2005, trazendo para o contexto da formação em saúde a inovação pedagógica e a compreensão de que a doença de cada paciente não se inicia e nem termina no indivíduo ou no atendimento realizado no consultório, mas constitui uma inter-relação complexa na qual interferem fatores econômicos, culturais, sociais e políticos ${ }^{25}$.

A análise do material textual constituído pelos estudantes do Seminário de Integração IV, no período de 2006 a 2013, mostrou que a proposta avançou enquanto atividade de ensino inovadora baseada na integração curricular e na interdisciplinaridade, tanto em quantidade de informações registradas pelos estudantes de graduação, quanto em relação ao aprendizado focado no paciente e em suas necessidades. Com o desenvolvimento do Seminário no currículo, desde sua implantação, observa-se, pela análise das narrativas e apresentações produzidas pelos grupos de tutoria no período estudado, a mudança de um olhar fragmentado para um olhar mais amplo 
do paciente, buscando a vinculação de sua queixa principal com seu contexto social.

As evidências para esses ganhos e mudanças têm como base a análise e discussão da estratégia metodológica de narrativas orientadas por professores tutores de diferentes áreas do conhecimento. A estratégia promoveu a qualificação dos relatos por meio do olhar interdisciplinar sobre o cuidado em saúde nos pacientes acompanhados, possibilitando a compreensão dos contextos mais amplos, diferenciados e complexos das experiências das pessoas, e o modo específico como elas constroem e dão significado a essas vivências ${ }^{12}$. As narrativas construídas pelos estudantes de graduação sobre o "caso clínico" extrapolaram o olhar sobre o indivíduo como objeto de estudo e aproximaram-se do ser humano, passando por sua queixa principal, sua história de vida, e nela ganhando significado e legitimidade.

A valorização das narrativas dos pacientes é um elemento-chave para uma clínica voltada para a integralidade do cuidado em saúde. Trazer as narrativas para a clínica facilita a percepção e a interpretação do significado do processo de adoecimento como um modo e permite ao profissional da saúde incorporar novos enunciados ao seu repertório interpretativo e, assim, ampliar a dimensão dialógica, hermenêutica e integral do saber e da prática clínica ${ }^{12}$.

Informações voltadas ao contexto familiar dos pacientes, histórico familiar de doenças, hábitos comportamentais, história de vida (relatos de violência doméstica, preconceito) e o registro de aspectos subjetivos do indivíduo (percepção sobre a condição de saúde bucal, comportamento durante as consultas odontológicas) passaram a fazer parte do cuidado em saúde, constituindo um olhar integral e interdisciplinar em relação ao paciente.

Nesse sentido, a intervenção técnica de núcleo articula-se com o cuidar quando o sentido da intervenção passa a ser não apenas o alcance de um estado de saúde visado de antemão, nem somente a aplicação mecânica das tecnologias disponíveis para alcançar este estado. O cuidado refere-se ao desenvolvimento de atitudes e relacionamentos entre pacientes e profissionais de saúde, com base na intersubjetividade e no exercício de uma sabedoria prática para a saúde. Esses aspectos devem ser apoiados na tecnologia, mas não podem se resumir a ela ${ }^{26}$.

Esses estudantes, ao concluírem a terceira etapa da formação do cirurgião-dentista, já tendo experienciado quatro Seminários de Integração - os quais se organizam em eixos integradores de saberes/áreas/professores/estudantes de cada semestre -, assumem, em sua trajetória acadêmica, o pressuposto da problematização das situações de aprendizagem, possibilitando a discussão de situações clínicas diversas, na perspectiva de diferentes olhares disciplinares.

Ao chegar à quarta etapa do currículo, o estudante de Odontologia ingressa no espaço de aprendizado clínico já tendo a interdisciplinaridade como um dos princípios metodológicos do trabalho em saúde, o qual leva em conta os conhecimentos prévios dos estudantes e possibilita o desenvolvimento de competências que potencializem seu conhecimento. Durante o período de imersão nas Clínicas Integradas da quinta à oitava etapa do curso, a experiência do Seminário de Integração tem continuidade e é reforçada nos Seminários Clínicos, perpassando a formação do estudante de Odontologia.

É preciso reconhecer que, embora ganhos sejam percebidos pelos estudantes do curso de Odontologia da UFRGS tanto com a estratégia pedagógica do Seminário de Integração quanto com as atividades de ensino que buscam a integração curricular como um todo ${ }^{27}$, as mudanças curriculares acontecem em processo, e a prática interdisciplinar no ensino em saúde ainda constitui um desafio que deve ser construído no cotidiano do desenvolvimento curricular, de modo transversal a esse currículo, numa relação de reciprocidade e de mutualidade entre os diversos campos do conhecimento ${ }^{28}$. É uma experiência pedagógica nova para os estudantes e especialmente para os professores, que, muitas vezes, foram formados por currículos fragmentados por especialidades e que veem no Seminário de Integração uma oportunidade de educação permanente da sua prática docente.

A possibilidade da formação em saúde a partir de um currículo baseado na interdisciplinaridade tem a potencialidade de resgatar o caráter de totalidade do conhecimento, das interações complexas onde todos os conceitos e teorias estão conectados entre si. Da mesma forma, facilita a compreensão de que os indivíduos aprendem usando a razão, o intelecto, mas também a intuição, as sensações, as emoções e os sentimentos ${ }^{29}$.

Sugere-se realizar novas pesquisas no sentido de acompanhar o processo de desenvolvimento curricular dos estudantes até a conclusão do curso de graduação, para que a experiência concreta de currículos "inovadores" e pautados na busca da interdisciplinaridade, nesta e em outras instituições de educação superior do País, possa trazer mudanças efetivas no cuidado em saúde. Na mesma perspectiva de estudos complementares, os egressos do curso, muitos dos quais estão inseridos em residências multiprofissionais, atividades de preceptoria, programas de pós-graduação stricto sensu com ênfase no SUS e nos serviços da rede SUS, também devem ser incluídos em pesquisas que possam avaliar de que modo as experiências curriculares interdisciplinares afetam o fazer e a resolutividade em saúde. 
“Mudança conceitual requer mudança de posturas. Se a atitude não acompanha as mudanças conceituais, o resultado poderá ser uma interdisciplinaridade apenas pontual" (p. 76) ${ }^{30}$.

\section{CONSIDERAÇÕES FINAIS}

A análise do material produzido no Seminário de Integração IV, de 2006 a 2013, possibilitou a compreensão do olhar do estudante da graduação em Odontologia sobre o paciente e sobre o cuidado em saúde a partir de uma atividade de ensino interdisciplinar.

A inclusão das narrativas, como estratégia metodológica do seminário, trouxe a qualificação dos relatos por meio da problematização das situações de aprendizagem e da discussão de situações clínicas diversas, na perspectiva de diferentes olhares disciplinares, extrapolando a descrição do "caso clínico" enquanto objeto de estudo e aproximando os estudantes de graduação em Odontologia do ser humano a ser cuidado, passando por sua queixa principal, história de vida e subjetividades.

\section{REFERÊNCIAS}

1. Ditterich RG, Portero PP, Schmidt LM. A preocupação social nos currículos de odontologia. Rev ABENO 2007; (1): 58-62.

2. Fagundes NC, Fróes Burhnam T. Transdisciplinaridade, multirreferencialidade e currículo. Rev FACED 2011; (5):39-55.

3. Brasil. Conselho Nacional de Educação. Resolução CNE/ CES 3/2002, de 19 de fevereiro de 2002. Institui as Diretrizes Curriculares Nacionais do Curso de Graduação em Odontologia. Brasília, 4 mar 2002; Seção 1, p. 10.

4. Saupe R, Cutolo LRA, Wendhausen ALP, Benito GAV. Competência dos profissionais da saúde para o trabalho interdisciplinar. Interface comum saúde educ 2005; 9(18): 531-36.

5. Lemos CLS, Fonseca SG. Saberes e práticas curriculares: um estudo de um curso superior na área da saúde. Interface comum saúde educ 2009; 13(28):57-69.

6. Universidade Federal do Rio Grande do Sul. Faculdade de Odontologia. Projeto Político Pedagógico. Porto Alegre, 2005.

7. Warmling CM, Rossoni E, Hugo FN, Toassi RFC, Lemos VA, Slavutzky SMB, et al. Estágios curriculares no SUS: experiências da Faculdade de Odontologia da UFRGS. Rev ABENO 2011; 11(2):63-70.

8. Minayo MCS. O desafio do conhecimento. Pesquisa qualitativa em saúde. São Paulo: HUCITEC; 2007.

9. Mendes JMR, Lewgoy AMB, Silveira EC. Revista ciência e saúde. Porto Alegre 2008; 1(1):24-32.
10. Onocko-Campos RT, Palombini AL, Leal E, Serpa Junior OD, Baccari IOP, Ferrer AL, et al. Narrativas no estudo das práticas em saúde mental: contribuições das perspectivas de Paul Ricoeur, Walter Benjamim e da antropologia médica. Ciência saúde coletiva 2013; 18(10):2847-57.

11. Dasgupta S. Las historias importan: Narrativa, Salud y Justicia Social. Conexión pediátrica 2012; 5(1): 1-4.

12. Favoreto $\mathrm{CAO}$, Camargo Júnior KR. A narrativa como ferramenta para o desenvolvimento da prática clínica. Interface comum saúde educ 2011; 15(37):473-83.

13. Onocko-Campos RT, Furtado JP. Narrativas: utilização na pesquisa qualitativa em saúde. Rev saúde pública 2008; 42(6):1090-6.

14. Bardin L. Análise de conteúdo. 70 ed. São Paulo: Almedina; 2011.

15. Braid LMC, Machado MFAS, Aranha ÁC. Estado da arte das pesquisas sobre currículo em cursos de formação de profissionais da área da saúde: um levantamento a partir de artigos publicados entre 2005 e 2011. Interface comum saúde educ 2012; 16(42):679-92.

16. Junqueira CR, Ramos DIP. Aspectos éticos da percepção de pacientes em atendimento odontológico. Rev bras ciênc saúde 2007;11:95-102.

17. Brasil. Ministério da Saúde. Secretaria de Atenção à Saúde. Núcleo Técnico da Política Nacional de Humanização. Humaniza SUS: Documento base para gestores e trabalhadores do SUS. 4. ed. 4. reimp. Brasília: Ministério da Saúde, 2010. 72p.

18. Silva AC, Fonseca AM, Silva JLL, Góes FGB, Cunha FTS. Refletindo sobre a integralidade no cuidado de enfermagem: estudo bibliográfico. Online braz j nurs. 2006. 5(3) [capturado 26 dez. 2014]; 1-9. Disponível em: http:/ /www.uff.br/ objnursing/index.php/nursing/article/view/442/104

19. Brasil. Lei de Diretrizes e Bases da Educação Nacional. Lei no 9.394, de 20 de dezembro de 1996. Estabelece as diretrizes e bases da educação nacional. Brasília, 20 dezembro 1996 [capturado 26 dez. 2014]; 1-9. Disponível em: http:/ / portal.mec.gov.br/arquivos/pdf/ldb.pdf

20. Junqueira CR, Junqueira SR, Almeida FCS, Zilbovicius C, Araujo ME, Ramos DLP. A formação humanística, social e ética do graduando em odontologia. Rev bras ciênc saúde $2011 ; 14(4): 25-36$.

21. Fagundes NC, Burnham TF. Discutindo a relação entre espaço e aprendizagem na formação de profissionais de saúde. Interface comum saúde educ 2005; 9(16):105-14.

22. Stella RCR, Puccini RF. A formação profissional no contexto das Diretrizes Curriculares nacionais para o curso de medicina. In: Puccini RF, Sampaio LO, Batista NA, orgs. A formação médica na Unifesp: excelência e compromis- 
so social [online]. São Paulo: Editora Unifesp; 2008. p. 5369. [capturado 26 dez. 2014]. Disponível em: http: / / books. scielo.org/id/q8g25/pdf/puccini-9788561673666-04.pdf

23. Hayacibara MF, Lolli LF, Terada RSS, Hidalgo MM, Bispo CGC, Terada HH, et al. Experiência de Clínica Ampliada em Odontologia na Universidade Estadual de Maringá. Rev bras educ med [on line].2012. 36 (1 Supl. 2) [capturado 26 dez. 2014]; 178-83. Disponível em: http:/ / www.scielo. br/pdf/rbem/v36n1s2/a26v36n1s2.pdf

24. Pedrosa JI. Iniciação às práticas de saúde: bricolagem na seleção de conteúdos. Rev bras educ med [on line]. 2013. 37 (3) [capturado 26 dez. 2014]; 408-17. Disponível em: http:/ / www.scielo.br/pdf/rbem/v37n3/13.pdf

25. Poi WR, Tagliavini RL, Sonoda CK, Castro JCM, Salineiro SL, Pedrini D, et al. O perfil da disciplina de clínica integrada da faculdade de odontologia de Araçatuba UNESP, após onze anos de implantação. Arq odontol 1997; 33(1):35-47.

26. Ayres JRCM. Cuidado e reconstrução das práticas de saúde. Interface comun saúde educ set 2003/fev 2004;8(14):73-91.

27. Toassi RFC, Souza JM, Baumgarten B, Rösing CK. Avaliação curricular na educação superior em odontologia: discutindo as mudanças curriculares na formação em saúde no Brasil. Rev ABENO 2012; 12(2):170-7.

28. Fazenda ICA. Interdisciplinaridade: História, teoria e pesquisa. Campinas: Papirus; 1976.
29. Thiesen JS. A interdisciplinaridade como um movimento articulador no processo ensino-aprendizagem. Rev bras educ 2008; 13 (39):545-98.

30. Santos A. Complexidade e transdisciplinaridade em educação: cinco princípios para resgatar o elo perdido. Rev bras educ 2008; 13(37):71-83.

\section{CONTRIBUIÇÃO DOS AUTORES}

Ramona Fernanda Ceriotti Toassi participou de todas as etapas do trabalho, além de redigir e revisar o artigo, Danielle Stoffels, Isabela Polesi Bergamaschi e Alessandra Dutra da Silva participaram da revisão de literatura, organização e análise dos resultados, e revisão do artigo. Pantelis Varvaki Rados fez a concepção ideológica do trabalho e participou da análise dos resultados e da revisão final do artigo.

\section{CONFLITO DE INTERESSES}

Não há conflito de interesses.

\section{ENDEREÇO PARA CORRESPONDÊNCIA}

Ramona Fernanda Ceriotti Toassi

Rua Ramiro Barcelos, 2492 - Porto Alegre

CEP 90035-003 - RS

E-mail: ramona.fernanda@ufrgs.br 